\title{
Continuous and Short Fiber Reinforced Composite in Root Post-Core System of Severely Damaged Incisors
}

\author{
Sufyan Garoushi*, Pekka K.Vallittu and Lippo V.J. Lassila
}

Department of Prosthetic Dentistry \& Biomaterials Science, Institute of Dentistry, University of Turku, Turku, Finland

\begin{abstract}
Purpose: The aim of this study was to determine the static load-bearing capacity of endodontically treated maxillary incisors restored with post-core complex made of experimental fiber composite resin (FC) and complete crown made of particulate filler composite (PFC). Further aim was to evaluate the effect of FC resin on the failure mode of the restoration.

Material and Methods: The experimental composite resin (FC) was prepared by mixing $22.5 \mathrm{wt} \%$ of short E-glass fibers ( $3 \mathrm{~mm}$ in length) and $22.5 \mathrm{wt} \%$ of semi-interpenetrating polymer network (IPN) resin with $55 \mathrm{wt} \%$ of silane treated silica fillers. Thirty extracted sound upper central incisors were used. Twenty teeth were prepared by cutting the clinical crown $2 \mathrm{~mm}$ above the cemento-enamel junction horizontally. Restorations were made by two techniques ( $\mathrm{n}=10)$. Group A (control group) contained samples of sound incisor teeth. Group B had teeth restored using glass fiber post (everStick, StickTeck) and PFC (Filtek Z250, 3M-ESPE) to build up core and complete crown. In Group C, the teeth were restored with FC as post-core and complete crown of PFC. The root canals were prepared and posts were cemented with a dual cure resin cement. The restorations were polymerized with a hand-light curing unit. All restored teeth were stored in water at room temperature for $24 \mathrm{~h}$ before they were statically loaded with speed of $1.0 \mathrm{~mm} / \mathrm{min}$ until fracture. Data were analyzed using ANOVA ( $\mathrm{p}=0.05)$. Failure modes were visually examined.

Results: ANOVA revealed that restored incisors (Group B and C) had a statistically significantly lower load-bearing capacity $(\mathrm{p}<0.05)$ than the control group. Restorations made from FC post-core and PFC coverage (Group C) gave force value of $363 \mathrm{~N}$ (112 SD), which was higher than the value of Group B (211 N, 50 SD).

Conclusions: Within the limitations of this study, the teeth restored with experimental fiber composite post-core demonstrated higher load bearing capacity than those with fiber post and PFC core.
\end{abstract}

Key Words: Load-bearing capacity, experimental fiber composite, post-core, complete composite crown.

\section{INTRODUCTION}

Endodontically treated teeth often require substantial build up with varying post-core foundation materials to retain a complete crown. In recent years various types of fiberreinforced composite resin posts have been introduced in order to provide the dental profession an alternative to cast or prefabricated metal posts for restoring endodontically treated teeth, as the elastic moduli of these fiber posts are closer to that of dentin than that of metal posts [1]. In restoring severely damaged dentition, it is important to restore strategically important teeth even though they may be severely damaged. By using adhesive techniques and particulate filler composite resin (PFC), as both core and veneering material, root filled teeth can in some instances be restored without conventional crown coverage [2]. A complete crown with a $2 \mathrm{~mm}$ ferrule on a sound tooth structure changed the distribution of forces to the root and the post-core complex [3]. One previous study reported that when bonded resin was used on structurally weakened roots, there was no statistical

\footnotetext{
*Address correspondence to this author at the Department of Prosthetic Dentistry and Biomaterials Science, Institute of Dentistry, University of Turku, Lemminkäisenkatu 2, FI-20520 Turku, Finland; Tel: + 358-2-33383-58; Fax: +358-2-333-83-90; E-mail: sufgar@utu.fi
}

difference in strength between post-core restorations that used a ferrule and those without a ferrule [3]. Many studies on the mechanical strength of pulpless incisors restored with fiber posts and PFC cores have shown lower incidences of root fractures in comparison with other types of post-core systems [3-5]. Although some clinical reports suggest that PFC core is a promising alternative to conventional treatment modalities [6,7], fracture of the composite resin core has also been reported as a reason for failure [8]. Due to failures of this type, using restorative composite resins in large high-stress bearing applications such as core structure remains controversial. The relatively high brittleness and low fracture toughness of current composite resins still limit their use in these large stress-bearing restorations [9]. Studies have been undertaken to improve restorative composite resins. Attempts have been made to change the type or size of fillers and their silanization, by changing the polymerization kinetics of resins and by influencing the degree of monomer conversion [10]. Reinforcing the resin with micro-glass fibers [11], whiskers [12], particulate ceramic fillers (dense and porous) [13], and optimization of filler content are among the methods that have been studied. Other aspects relating to indirect laboratory-made composite resins have been investigated using post-polymerizing to enhance composite resin strength and toughness [14]. 
For over 30 years, glass fibers have been investigated to reinforce dental polymers [15]. Glass fibers have documented reinforcing efficiency and good esthetic qualities compared to carbon or aramid fibers [16]. The effectiveness of fiber reinforcement is dependent on many variables, including the resins used, the quantity of fibers in the resin matrix [17,18], length of fibers [18], form of fibers [19], orientation of fibers [20], adhesion of fibers to the polymer matrix [21], and impregnation of fibers with the resin [22]. Short random fibers provide an isotropic reinforcement effect in multidirections instead of 1 or 2 directions, as described by Krenchel [23].

It can be hypothesized that by using of short E-glass fiber fillers, the composite resin restoration can sustain loads required for post-core restorations.

Poly (methyl methacrylate) (PMMA) based semiinterpenetrating polymer network (semi-IPN) matrix has been used in denture base materials [24, 25]. Some products of dental fiber-reinforced composites (FRCs) also use semiIPN-polymer matrix [25]. However, dental restorative composite resin of semi-IPN-polymer matrix in combination with glass fibers has not been evaluated. Thus, the first aim of this study was to investigate the load-bearing capacity of post-core restorations made of experimental short fiberreinforced composite resin (FC) with semi-IPN-matrix. The second aim was to investigate the effect of FC composite on the failure mode of the restoration.

\section{MATERIALS AND METHODS}

The materials used in the study are listed in Table $\mathbf{1 .}$ Experimental fiber-reinforced composite resin (FC) was prepared by mixing $22.5 \mathrm{wt} \%$ of short E-glass fibers $(3 \mathrm{~mm}$ in length, $15 \mu \mathrm{m}$ in diameter, and coated with bisphenol Aglycidyl dimethacrylate BisGMA\} and PMMA matrix) to $22.5 \mathrm{wt} \%$ of photopolymerizable dimethacrylate resin matrix and then $55 \mathrm{wt} \%$ of filler particles of silica $\left(\mathrm{SiO}_{2}\right)(3 \pm 2 \mu \mathrm{m}$ in size) (Aldrich, Steinheim, Germany) were gradually added. Mixing was performed using a high speed mixing machine for $5 \mathrm{~min}$ (SpeedMixer, DAC, Germany, 3500 $\mathrm{rpm})$. Before the silica filler particles were incorporated into the resin matrix, they were silane treated, as described previously [26]. The dimethacrylate based resin matrix containing PMMA formed a semi-IPN polymer matrix for the experimental fiber composite (FC).

\section{Specimen Preparation}

Thirty extracted human maxillary central incisors with straight roots and completely formed apices were selected on the basis of similar root sizes, absence of caries in the root, a crown up to $2 \mathrm{~mm}$ above the cemento-enamel junction (CEJ), and absence of visible fracture lines in the root. The teeth were stored in water until further processing. Root lengths were measured with a digital caliper (Tamoline, Helsinki, Finland) with an accuracy of $0.01 \mathrm{~mm}$ from CEJ on the facial surface, and mesiodistal widths were measured between the proximal surfaces at the CEJ. The clinical crowns of twenty incisors were removed up to approximately $2 \mathrm{~mm}$ above the CEJ using 1000-grit (FEPA) silicon carbide abrasive paper (Struers, Copenhagen, Denmark) at $300 \mathrm{rpm}$ under water cooling using an automatic grinding machine (Struers Rotopol-11) according to ISO/TR standard 11405 [27].

The teeth were divided into three groups $(n=10)$. Postcore and direct composite resin crowns were fabricated according to the groups they belonged (Fig. 1). Group A: made of intact, sound incisor teeth (control group), Group B: made from glass fiber post (everStick, StickTeck) and particulate filler composite resin (PFC) (Filtek Z250, 3M-ESPE) as core and complete crown, Group $\mathrm{C}$ : made from FC post-core complex and PFC complete crown. For both groups B and $\mathrm{C}$ complete crowns were made of Filtek Z250.

\section{Root Canal and Tooth Preparation}

Post space preparations ( $8 \mathrm{~mm}$ deep from CEJ) were made with Parapost drills (Parapost stainless drills; Coltène/ Whaledent, Mahwah, NJ, USA) (diameter $1.5 \mathrm{~mm}$ ) using laboratory hand piece micro motor (Ultimate $500 \mathrm{~K}$, NSK, JAPAN) under water cooling. Root canal obturation procedures were not accomplished. Each tooth was prepared for a complete veneer crown with a $1.5 \mathrm{~mm}$ wide shoulder by

Table I. Materials Used in the Study

\begin{tabular}{|c|c|c|c|}
\hline Brand & Manufacturer & Lot No. & Composition \\
\hline Filtek Z250 & $\begin{array}{l}\text { 3M-ESPE, } \\
\text { St paul, MN, USA }\end{array}$ & 20040420 & $\begin{array}{l}\text { Bis-GMA, UDMA, } \\
\text { Bis-EMA }\end{array}$ \\
\hline Bifix QM & VOCO, Cuxaven, Germany & 600429 & \\
\hline 1. Primer & & & 1. HEMA, Bis-GMA, water \\
\hline everStick & StickTeck Ltd, Turku, Finland & 2050426-ES-125 & $\begin{array}{l}\text { PMMA, Bis-GMA } \\
\text { E-glass fibers }\end{array}$ \\
\hline Parapost Fiber & Coltène/Whaledent, Mahwah, NJ, USA & MT-4816 & E-glass fibers, resin matrix, fillers \\
\hline
\end{tabular}

PMMA, poly methyl methacrylate, $\mathrm{M}_{\mathrm{w}} 220.000$. Bis-GMA, bisphenol A-glycidyl dimethacrylate. UDMA, urethane dimethacrylate.

Bis-EMA, bisphenol A polyethylene glycol diether. HEMA, hydroxyethyl methacrylate. 


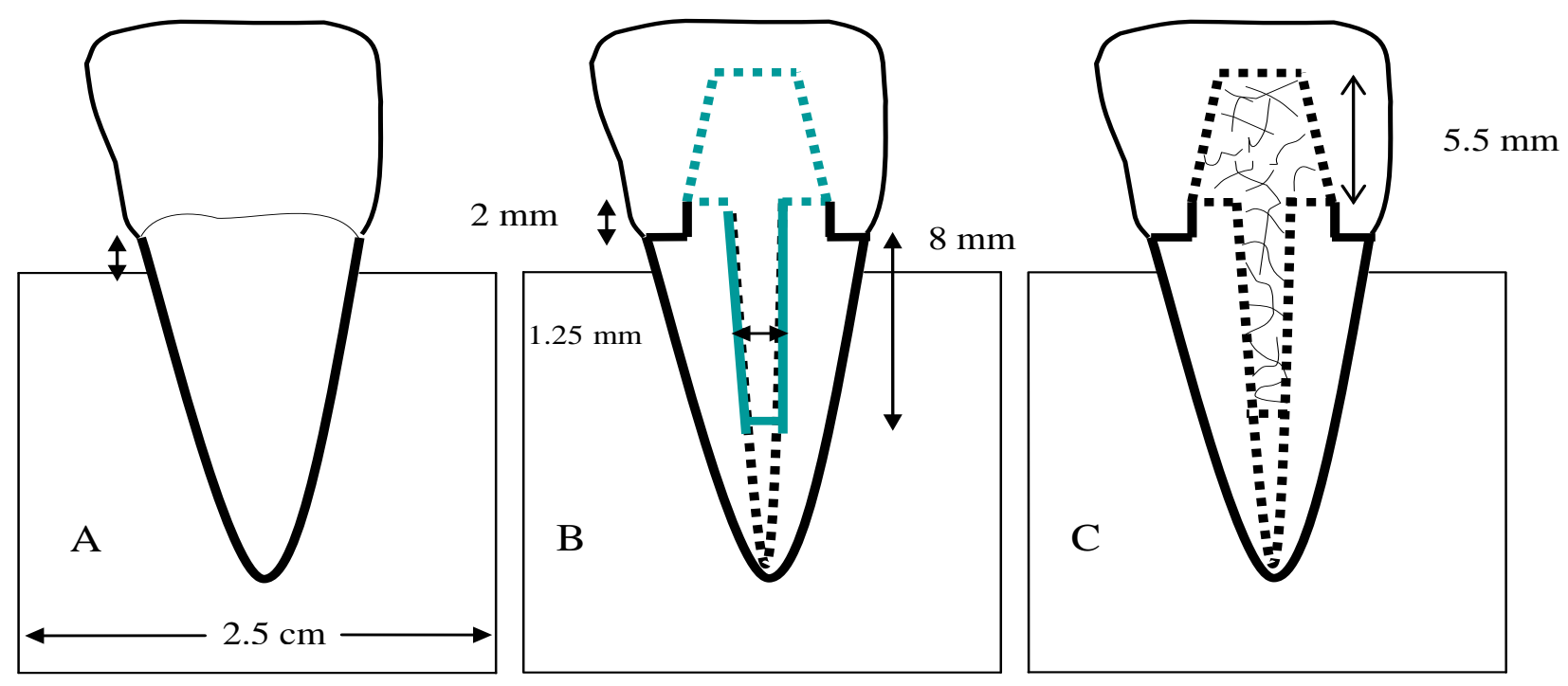

Fig. (1). Schematic figure representing test groups. PFC, particulate filler composite; FC, experimental fiber composite.

using a diamond stone (No. 6847-31-061 Size 016, Brasseler, Savannah, Ga.) and high speed handpiece (TradionalL-Fiber-Optic Handpiece No. 780045, Midwest Dental Products, Des Plaines, III.) with copious water-air coolant. The finishing line of each preparation was located at the CEJ. Preparations were made freehand by one operator with a subjective angle of 8 to 10 degrees. The root canal and remaing crown structure were etched with $37 \%$ phosphoric acid and bonded with enamel/dentin bonding system according to manufacturer's instructions. A light curing device (Optilux-501, Kerr, CT, USA) was used. The wavelength of the visible light (halogen) was between 380 and $520 \mathrm{~nm}$ with maximal intensity at $470 \mathrm{~nm}$ and light irradiance at 800 $\mathrm{mW} / \mathrm{cm}^{2}$.

\section{Post and Core Fabrication}

For group B, Glass fiber posts (FiberWhite-Parapost) were cemented with a dual-cured composite resin cement (ParaCem Universal, Switzerland) (according to manufacture's instructions) into the etched, bonded canal with a lentulo-spiral drill [28]. Each post was placed to full depth and excess cement removed. The cement was light-cured (in $45^{\circ}$ angle, close to the root of the post) for $40 \mathrm{~s}$. The posts were extending $4 \mathrm{~mm}$ above the coronal surface of the prepared teeth. PFC cores extending $5.5 \mathrm{~mm}$ incisal to the sectioned tooth surfaces were buildup and polymerized incrementally (40 s per $2 \mathrm{~mm}$ ).

For group $\mathrm{C}, \mathrm{FC}$ posts were made by condense and polymerize the experimental fiber composites resin into the prepared canals incrementally. FC cores were fabricated and polymerized as described previously.

\section{Complete Crown Fabrication}

Crown construction was designed in order to simulate chair-side fabricated technique with light cured PFC. In order to minimize variations in specimens, a transparent template matrix (Memosil 2, Heraeus Kulzer, Germany) of an ideally contoured crown was used to aid crown fabrication. Polymerization was performed incrementally using a lightpolymerization unit for $40 \mathrm{~s}$ from both sides. The light source was placed in close contact (1-2 mm) with crown surface. Finally, the cervical outline of the composite resin crown and the surface of the restoration were finished using diamond stone and polishing tips (40000 cycles $\mathrm{min}^{-1}$ with water-cooling). After finishing the restorative procedure, the teeth were mounted into acrylic resin (Palapress; Heraus Kulzer, Wehrheim, Germany) block (diameter $2.5 \mathrm{~cm}$ ). The flattened incisal root surface was located approximately 1.5 $\mathrm{mm}$ above the acrylic resin level (to simulate bone). During the entire procedure, the teeth were maintained in a wet environment and then stored in distilled water at room temperature for $24 \mathrm{~h}$ before testing.

\section{Fracture Load Test to Measure the Load Bearing Capac- ity}

A static load was applied to the restored teeth with a universal testing machine (model LRX, Lloyd Instruments Ltd, Fareham, UK) at a speed of $1.0 \mathrm{~mm} / \mathrm{min}$. The acrylic block containing the restored tooth was tightly fixed to the inclined metal base to provide a 45 -degree angle between the palatal surface of the tooth and the loading tip (spherical Ø $2.0 \mathrm{~mm}$ ) (Fig. 2). The loading event was registered until fracture for each tooth and the failure mode for each specimen was visually analyzed and categorized to 2 typical types of failures: favorable type above the CEJ which has easy possibility to repair (portion of the core fractured, or failure occurred at core-tooth interface) and unfavorable type below the CEJ (vertical root fracture) with difficult chance to repair.

\section{Statistical Analysis}

Data of the fracture-load values were statistically analyzed with SPSS version 10 (SPSS Inc, Chicago, IL, USA) using analysis of variance (ANOVA) followed by the Tukey's post hoc test at a significance level of 0.05 to determine the differences between the groups.

\section{RESULTS}

Fig. (3) summarizes the mean fracture loads and standard deviations for the test groups. Restorations made from FC post-core (Group C) gave higher fracture load values (363 N) 
than those with fiber post and PFC core (Group B) $(211 \mathrm{~N})$. ANOVA revealed that restored teeth (Group B and C) had a statistically significant lower load-bearing capacity $(\mathrm{p}<0.05)$ than the control group. However, the difference in the failure mode was clear. Fracture pattern analysis indicated that $70 \%$ of specimens in Group C (FC post-core) were favorable, whereas in Group B (fiber post and PFC core) the failures were unfavorable (Table 2).

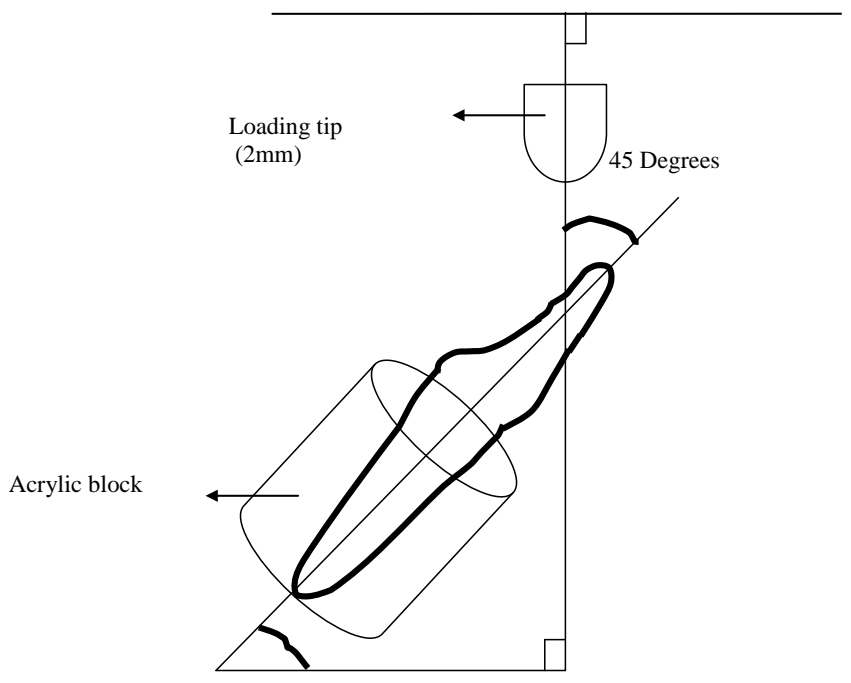

Fig. (2). Schematic drawing of test specimens subjected to load at 45 degrees.

\section{DISCUSSION}

Results obtained in this investigation supported the hypotheses of using short E-glass fiber fillers to reinforce the composite resin in order to sustain loads of post-core restorations. This study simulated the worst case scenario of endodontically treated maxillary incisors with severely damaged crowns. Conventional treatment would have involved a metal post-core and a complete crown. Conversely, clinical studies on failure of metal post-core restorations often reported the incidence of root fracture $[3,4]$. Composite resin or amalgam would have been alternative core materials. Good long-term clinical performance of endodontically treated teeth restored with a combination of fiber post and composite resin core in combination to dentin bonding were reported [7]. However, another study has reported lower long-term survival rates with the primary cause of failure being fracture of the composite resin core, especially in high stress-bearing areas [8]. For better performance of post, materials for fabricating post should have certain physical characteristics, such as strength and modulus of elasticity, which

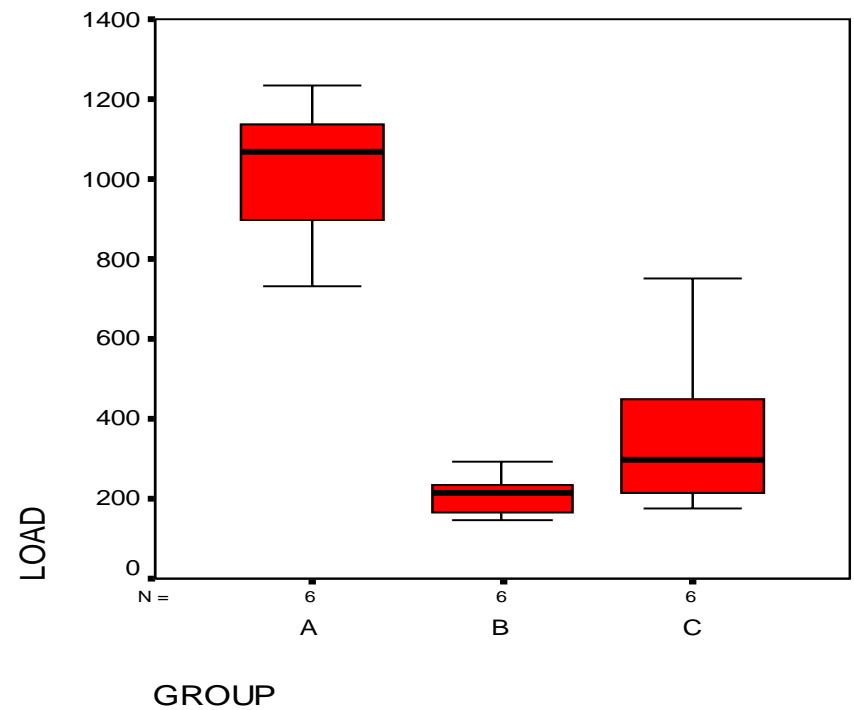

Fig. (3). Mean values of load-bearing capacity $(\mathrm{N})$ of test specimens. Horizontal line above the boxes indicates groups that do not differ statistically from each other.

are important with respect to preservation and fracture strength of tooth structure. In other words, the diameter of the post should be minimized, but sufficient to resist functional forces [29]. The selection of core materials should be based on the capability of transmitting the functional stress effectively. From this point of view, using similar material as post-core complex would be beneficial. Recently, it has been shown that the use of semi-IPN matrix in combination with short glass fibers in restorative filling composite resin has been made with encouraging results [30-32]. Thus, it was hypothesized that using short E-glass fiber fillers could reinforce the composite resin to maintain loads of post-core res-

Table 2. Failure Modes Distribution of Test Specimens

\begin{tabular}{|l|c|c|c|}
\hline \multirow{2}{*}{ Group } & \multicolumn{2}{|c|}{ Favorable Failures } & Unfavorable Failures \\
\cline { 2 - 4 } & Portion of the Core Fractured & Debonding at Core-Tooth Interface & Root Fracture \\
\hline \hline A (control) & 0 & 0 & 10 \\
\hline B (fiber post+PFC core) & 1 & 2 & 7 \\
\hline C (FC post+core) & 4 & 3 & 3 \\
\hline
\end{tabular}

$\mathrm{PFC}=$ Particulate filler composite resin.

$\mathrm{FC}=$ Experimental fiber composite resin. 
torations. The results of the loading test revealed substantial improvement in the load bearing capacity of dental composite resin reinforced with short E-glass fiber fillers (Group C) in comparison with conventionally used restorative composite resins (Group B). In order for the fiber to act as an effective reinforcement for polymers, stress transfer from the polymer matrix to the fibers is essential [11], and is achieved by having fiber length equal to or greater than the critical fiber length [11]. Based on this knowledge, the present study used fiber fillers $3 \mathrm{~mm}$ in length. In theory, the reinforcing effect of the fiber fillers is based not only on stress transfer from the polymer matrix to the fibers, but also on the behavior of individual fibers as stress breakers.

In the literature, the maximum incisal forces of anterior teeth varied, but the amount was almost around $200 \mathrm{~N}$, which is lower than the failure loads of FC post-core restorations $(363 \mathrm{~N})$ found in this study [33]. Therefore, it may be suggested that anterior teeth with a $2 \mathrm{~mm}$ ferrule, restored with FC post-core complex, would resist normal occlusal forces. However, this study did not consider the influence of parafunctional habits such as bruxism.

In this in vitro study, lateral forces were applied to the incisal surface using a $45^{\circ}$ angle between palatal surface of the tooth and the loading tip. In order to simulate clinical conditions, lateral forces should be considered as well as axial forces and fatigue loading. Moreover, aging processes, such as alternate thermal stress, mechanical stress, wear, and water storage should also be taken into consideration. Stress applied to the teeth and dental restorations is generally low and repetitive rather than being isolated and impactive in nature. However, because of a linear relationship between fatigue and static loading, the compressive static test also gives valuable information concerning load-bearing capacity $[34,35]$.

Water storage could decrease the load-bearing capacity of the specimens. In the polymer matrix, water acts as a plasticizer increasing free volume and decreasing the glass transition temperature of the polymer matrix [36]. It has also been previously reported that there is a potential deteriorative effect of water on the interfacial adhesion between the polymer matrix to glass fibers through rehydrolysis of the silane coupling agent [36]. However, one previous study showed that water sorption of FC resin was at the similar to the conventional filling composite [30].

Another aspect that may lead to different fracture resistance values is the type of cementation and material used to cement the veneering crown. However, for this study no specific cement was used and the crowns were fixed solely by resin. The fracture resistance values determined by the various investigators were recorded under different measurement criteria. These criteria were either initial cracking that was interpreted as crack development or a drop in the load by an absolute or relative amount. For this study, the maximum force on the final fracture was determined. Catastrophic fracture patterns were analyzed visually and two types of fracture patterns were found. These occurred according to the post-core materials used. The majority $(70 \%)$ of failure mode observed with conventional techniques (Group B) (fiber post and PFC core) was unfavourable (root fracture). In general, our results are in agreement with previous laboratory studies, which showed that the majority of the speci- mens fractured in the unfavorable mode (root fracture) [4, 37]. Root fractures originate from regions with excessive stress concentrations and propagate by exploring mechanically weak areas in the restoration. The fractures could have originated from the adhesive interface between the core and root dentin, and propagated toward the post by suggesting weak dentin bonding. On the other hand, it was observed that groups with FC post-core complex (Group C) presented more favorable failure modes, which have easy possibility to repair. This is most likely due to multidirectional fiber orientation at interface between the core and root dentin, provided a stiffer structure and thus the ability to stop or arrest crack propagation, which leads to a favorable mode of failure [34].

It should be emphasized that the use of FC post-core complex is not a substitute for restorations made of metal post-and-core and complete ceramic crown. The results of this study suggest that the use of FC may offer one alternative to overcome some potential problems of composite postcore restoration in high stress-bearing applications.

\section{CONCLUSION}

Short glass fiber reinforced semi-IPN composite resin demonstrated improved load-bearing capacity of post-core restoration compared with conventional particulate filler restorative composite resin although values were lower than for intact teeth.

\section{REFERENCES}

[1] Qualtrough AJ, Mannocci F. Tooth-colored post system: a review. Oper Dent 2003; 28: 86-91.

[2] Grandini S, Goracci C, Tay FR, Grandini R, Ferrari M. Clinical evaluation of the use of fiber posts and direct resin restorations for endodontically treated teeth. Int J Prosthodont 2005; 18: 399-404.

[3] Saupe WA, Gluskin AH, Radke RA. A comparative study of fracture resistance between morophological dowel and cores and a resin-reinforced dowel system in the intraradicular restoration of structurally compromised roots. Quintessence Int 1996; 27: 483-91.

[4] Sirimai S, Riis DN, Morgano SM. An in vitro study of the fracture resistance and the incidence of vertical root fracture of pulpless teeth restored with post-and-core systems. J Prosthet Dent 1999; 81: 262-69.

[5] Fokkinga WA, Kreulen CM, LeBell- Rönnlöf AM, Lassila LV, Vallittu PK, Creugers NH. Fracture behavior of structurally compromised non-vital maxillary premolars restored using experimental fiber reinforced composite crowns. Am J Dent 2006; 19: 32632.

[6] Roeters JJ. Extended indications for directly bonded composite restorations: a clinician's view. J Adhes Dent 2001; 3: 81-7.

[7] Grandini S, Goracci C, Tay FR, Grandini R, Ferrari M. Clinical evaluation of the use of fiber posts and direct resin restorations for endodontically treated teeth. Int J Prosthodont 2005; 18: 399-404.

[8] Fraga RC, Chaves BT, Mello GS, Siqueira JF Jr. Fracture resistance of endodontically treated roots after restoration. J Oral Rehabil 1998; 25: 809-13.

[9] Bayne SC, Thompson JY. Mechanical property analysis of two admixed PRIMM-modified commercial dental composites. Trans Acad Dent Mater 1996; 9: 238.

[10] Matinlinna JP, Lassila LVJ, Özcan M, Yli-Urpo A, Vallittu PK. An Introduction to Silanes and Their Clinical Applications in Dentistry. Int J Prosthodont 2004; 17: 155-64.

[11] Petersen RC. Discontinuous fiber-reinforced composites above critical length. J Dent Res 2005; 84: 365-70.

[12] Xu HH, Quinn JB, Smith DT, Giuseppetti AA, Eichmiller FC. Effect of different whiskers on the reinforcement of dental resin composites. Dent Mater 2003; 19: 359-67.

[13] Zandinejad AA, Atai M, Pahlevan A. The effect of ceramic and porous fillers on the mechanical properties of experimental dental composites. Dent Mater 2006; 22: 382-87. 
[14] Loza-Herrero MA, Rueggeberg FA, Caughman WF, Schuster GS, Lefebvre CA, Gardner FM. Effect of heating delay on conversion and strength of a post-cured resin composite. J Dent Res 1998; 77: 426-31.

[15] Vallittu PK. A review of fiber-reinforced denture base resins. J Prosthet Dent 1996; 5: 270-6.

[16] Vallittu PK, Narva K. Impact strength of a modified continuous glass fiber-poly (methyl methacrylate). Int J Prosthodont 1997; 10: 142-8.

[17] Vallittu PK, Lassila VP, Lappalainen R. Acrylic resin-fiber composite-part I: The effect of fiber concentration on fracture resistance. J Prosthet Dent 1994; 71: 607-12.

[18] Stipho HD. Repair of acrylic resin denture base reinforced with glass fiber. J Prosthet Dent 1998; 80: 546-50.

[19] Ladizesky NH, Cheng YY, Chow TW, Ward IM. Acrylic resin reinforced with chopped high performance polyethylene fiber properties and denture construction. Dent Mater 1993; 9: 128-35.

[20] Dyer SR, Lassila LVJ, Jokinen M, Vallittu PK. Effect of fiber position and orientation on fracture load of fiber reinforced composite. Dent Mater 2004; 20: 947-55.

[21] Vallittu PK. The effect of void space and polymerization time on transverse strength of acrylic-glass fiber composite. J Oral Rehabil 1995; 22: 257-61

[22] Miettinen VM, Vallittu PK. Water sorption and solubility of glass fiber-reinforced denture polymethyl methacrylate. J Prosthet Dent 1997; $77:$ :531-4

[23] Vishu S. Handbook of plastic testing technology, 2nd ed. New York: JohnWiley; 1998. p. 546.

[24] Lastumäki TM, Lassila LV, Vallittu PK. The semi-interpenetrating polymer network matrix of fiber-reinforced composite and its effect on the surface adhesive properties. J Mater Sci Mater Med 2003;14: 803-9.

[25] Lassila LV, Tezvergil A, Lahdenperä M, Alander P, Shinya A, Vallittu PK. Evaluation of some properties of two fiber reinforced composite materials. Acta Odontol Scand 2005; 63: 196-204.
[26] Söderholm KJ, Yang MC, Garcea I. Filler particle leachability of experimental dental composites. Eur J Oral Sci 2000; 108: 555-60.

[27] International Standardization Organization, ISO 10477-1992(E). Polymer-based crown and bridge material. Geneva: ISO; 1992.

[28] Hilton TJ, Ferracane JL. As per manufacturer's instructions. J Esthet Restor Dent 2006; 18: 1-2.

[29] Xing ZY, Hong ZW, Yue LZ, Li WK. Fracture strength of customfabricated Celay all-ceramic post and core restored endodontically treated teeth. Chin Med J 2006; 119: 1815-20.

[30] Garoushi S, Vallittu PK, Lassila LVJ. Short glass fiber reinforced restorative composite resin with semi-interpenetrating polymer network matrix. Dent Mater 2007; 23: 1356-62.

[31] Garoushi S, Vallittu PK, Lassila LVJ. Use of isotropic short fiber reinforced composite with semi-interpenterating polymer network matrix in fixed partial dentures. J Dent 2007; 35: 403-8.

[32] Garoushi S, Vallittu PK, Lassila LVJ. Fracture resistance of short, randomly oriented, glass fiber-reinforced composite premolar crowns. Acta Biomater 2007; 3: 779-84

[33] Anusavice KJ. Phillips' science of dental materials. $11^{\text {th }}$ ed. St. Louis: Elsevier; 2003. p. 93-4, 598-603.

[34] Garoushi S, Lassila LV, Tezvergil A, Vallittu PK. Static and fatigue compression test for particulate filler composite resin with fiber-reinforced composite substructure. Dent Mater 2007; 23: 1723

[35] Naumann M, Sterzenbach G, Prőschel P. Evaluation of load testing of postendodontic restorations in vitro: linear compressive loading, gradual cycling loading and chewing simulation. J Biomed Mater Res B Appl Biomater 2005; 74: 829-34.

[36] Lassila LVJ, Nohrström T, Vallittu PK. The influence of short-term water storage on the flexural properties of unidirectional glass fiber-reinforced composites. Biomaterials 2002; 23: 2221-29.

[37] Hayashi M, Takahashi Y, Imazato S, Ebisu S. Fracture resistance of pulpless teeth restored with post-core and crowns. Dent Mater 2006; 22: 477-85.

(C) Garoushi et al.; Licensee Bentham Open.

This is an open access article licensed under the terms of the Creative Commons Attribution Non-Commercial License (http://creativecommons.org/licenses/ by-nc/3.0/) which permits unrestricted, non-commercial use, distribution and reproduction in any medium, provided the work is properly cited. 